\title{
Functional Groups Detection: Do Chemistry Teachers Demonstrate Conceptual Difficulties in Teaching?
}

By Benjamin Anim-Eduful \& Kenneth Adu-Gyamfi

University of Cape Coast

Abstract- The chemistry chief examiner of the West African Examination Council has complaint a lot about the weak performance of students on organic chemistry, including functional group detection. The study, therefore, investigated whether senior high school teachers who teach chemical concepts to students also demonstrated conceptual difficulties on functional group detection under organic qualitative analysis. The study adopted convergent mixed methods procedures to collect both quantitative and qualitative data from 47 chemistry teachers. The 47 teachers were sampled through multistage sampling procedures to respond to the Organic Qualitative Analysis Diagnostic Test for Teachers. The quantitative data was analyzed using means, standard deviations, and percentages to reflect no scientific understanding, partial scientific understanding, and scientific understanding of functional group detection. The qualitative data was open-coded and constantly compared to established teachers' alternative conceptions and factual difficulties on functional group detection.

Keywords: alternative conceptions; factual difficulties; functional groups; teachers.

GJHSS-G Classification: FOR Code: 930299

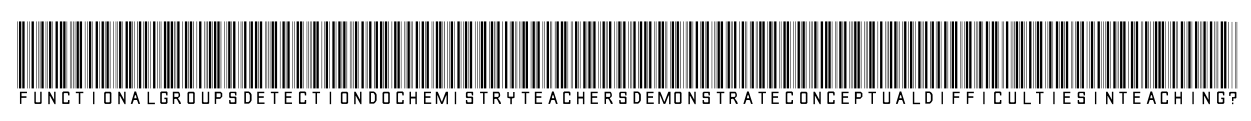

Strictly as per the compliance and regulations of:

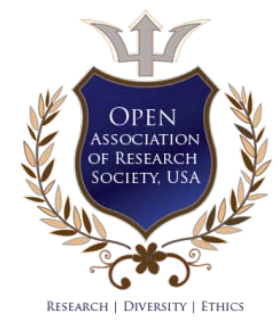

(C) 2021. Benjamin Anim-Eduful \& Kenneth Adu-Gyamfi. This is a research/review paper, distributed under the terms of the Creative Commons Attribution-Noncommercial 3.0 Unported License http://creativecommons.org/licenses/by-nc/3.0/), permitting all non-commercial use, distribution, and reproduction in any medium, provided the original work is properly cited. 


\title{
Functional Groups Detection: Do Chemistry Teachers Demonstrate Conceptual Difficulties in Teaching?
}

\author{
Benjamin Anim-Eduful ${ }^{\alpha}$ \& Kenneth Adu-Gyamfi ${ }^{\circ}$
}

\begin{abstract}
The chemistry chief examiner of the West African Examination Council has complaint a lot about the weak performance of students on organic chemistry, including functional group detection. The study, therefore, investigated whether senior high school teachers who teach chemical concepts to students also demonstrated conceptual difficulties on functional group detection under organic qualitative analysis. The study adopted convergent mixed methods procedures to collect both quantitative and qualitative data from 47 chemistry teachers. The 47 teachers were sampled through multistage sampling procedures to respond to the Organic Qualitative Analysis Diagnostic Test for Teachers. The quantitative data was analyzed using means, standard deviations, and percentages to reflect no scientific understanding, partial scientific understanding, and scientific understanding of functional group detection. The qualitative data was open-coded and constantly compared to established teachers' alternative conceptions and factual difficulties on functional group detection. Teachers demonstrated conceptual difficulties in the form of alternative conceptions and factual difficulties. It is, therefore, recommended that chemistry educators and researchers should design and develop instructional strategies that challenge alternative conceptions among teachers.
\end{abstract}

Keywords: alternative conceptions; factual difficulties; functional groups; teachers.

\section{INTRODUCTION}

$\Lambda$ nalysis of chemical compounds is one of the areas under chemistry that is classified into two categories. The two categories are quantitative analysis and qualitative analysis. The quantitative analysis finds the amounts of each atom of element or group present in a given solution whereas, the qualitative analysis finds the type of each atom of element or group present in a given sample of solution (Matthews, 2011). The qualitative analysis deals with the detections and identification of elements or group of atoms of elements present in a given solution. This qualitative analysis is also classified into two categories: an inorganic qualitative and organic qualitative analysis. The inorganic qualitative analysis is used to detect the presence of inorganic ions (anions and cations), and gases or compounds in an unknown sample, whereas organic qualitative analysis is used to establish the

Author a o: Department of Science Education, Faculty of Science and Technology Education, College of Education Studies, University of Cape Coast.e-mail: kenneth.adu-gyamfi@ucc.edu.gh presence or absence of particular functional groups as specified in the Ministry of Education [MOE] (2010) curriculum. According to Cooley and Williams (1999), qualitative analysis is of relevance and importance to learning chemistry as it improves students' chemistry concepts understanding. The qualitative analysis increases the conceptual understanding of chemical principles and the interactions of matter and its application in our daily lives. The qualitative analysis concepts are difficult for students to learn as their understanding requires process skills and an understanding of many chemistry concepts (Goh, Toh, \& Chia, 1987).

Organic chemistry is part of senior high school chemistry as its concepts are applied in our everyday lives (Yong, 1994). From the food we consume, dyes applied in our hair color, a medication used to treat sickness, and our everyday lives are rooted in core organic chemical processes (Rice, 2016). These applications of organic chemistry in our daily lives and the need for scientific progress necessitate constant attention to education in the field. Organic compounds have unique groups called functional groups. "Functional groups are individual atoms or groupings of atoms that are attached to the carbon chains or rings of organic molecules and give the molecules their characteristic properties" (Petrucci, Herring, Madura, \& Bissonnette, 2017, pp. 96.97). Functional group detection is a key in learning organic chemistry and that of organic qualitative analysis. Functional groups in organic chemistry at the senior high school level are hydrocarbons (alkanes, alkenes, alkynes, and benzene), alcohols $(-\mathrm{OH})$; aldehydes $(-\mathrm{CHO})$; ketones $(-\mathrm{C}=\mathrm{O})$; carboxylic acids $(-\mathrm{COOH})$; esters $(-\mathrm{COO}-)$; and amides $\left(-\mathrm{CONH}_{2}\right)$ (MOE, 2010). Functional group categorization is a common feature used by both higher and lower ability students for classifying organic compounds (Domin, Al-Masum, \& Mensah, 2008; Hassan, Hill, \& Reid, 2004). However, the categorization of organic compounds using functional groups is a difficulty for students. A study by Strickland, Kraft, and Bhattacharyya (2010) pointed out that many organic chemistry students could not explain vividly functional groups. To the students, all organic compounds appear to be very similar, as a molecule composed of carbon, hydrogen, and oxygen. 
According to O'Dwyer and Childs (2017), research studies comparing teachers' and learners' perspectives of organic chemistry are rare. Teachers often struggle to make students aware of these due to their complexities. This, perhaps, a contributing factor for many of studies, which identify students' and teachers' perception of organic chemistry as one of the most difficult areas of chemistry (Childs \& Sheehan, 2009; Greenbowe \& Schroeder, 2008). Chemistry concepts are related to the structure of matter, which is difficult for many students because chemistry curricula commonly incorporate many abstract concepts, which are central to further learning in both chemistry and other sciences (Taber, 2002). These abstract concepts are relevant because chemistry concepts or theories cannot be understood without these concepts insufficiently grasped by students (Coll \& Treagust, 2001). This abstract nature of chemistry, along and other content learning difficulties, means that chemistry contents require a high-level skill set (Taber, 2002).

Schwartz (1993) stated that, an aspect of acquiring new knowledge is comprehending the relationships between various related concepts. Likewise, Deci, Vallerand, Pelletier, and Ryan (1991) reported that learning is a combination of conceptual understanding and flexible use of knowledge. In this sense, modern teaching approaches indicate that permanent learning of chemistry concepts depends on the conceptual understanding of the teacher and the learner (Simsek, 2009). This implies that when concepts are used accurately and conveniently to establish relationships, these concepts are properly learned, the effective acquisition of knowledge is achieved. The problems that emerge when a relationship is not established between the concepts cause not only a failure in learning but also lead to alternative conceptions (Nakhleh, 1992).

Conceptual understanding is generally learning with understanding (Driver, Asoko, Leach, Scott, \& Mortimer, 1994). It is often contrasted with declarative knowledge learning, where the learner simply memorizes a relationship between things, events, or processes (Darmofal, Soderholm, \& Brodeur, 2002). To many, conceptual understanding entails just more than rote memorization of relationships; but requires the ability to apply previous learning across some kind of previously unexpected experiences (Smith \& Ragan, 1999). Unless prior knowledge is properly associated with new knowledge, learners may fail to correctly grasp new concepts, and this impedes meaningful learning (Bodner, 1986).

An awareness of the fact that alternative conceptions prevent meaningful learning has paved the way for studies that determine students' levels of conceptual understanding in science concepts including, those of chemistry (Adu-Gyamfi \& Ampiah, 2019; Adu-Gyamfi, Ampiah, \& Agyei, 2015). Conceptual understanding can promote students' learning and thus, has become an area of interest for educational research. Gaining insights into students' existing conceptions might help educators design effective teaching approaches targeting conceptual understanding. Determination of teachers and students' conceptual level in functional groups detection might also help educators in selecting the more effective teaching strategy that promotes conceptual understanding (Özkaya, Üce, Saricayir, \& Sahin, 2006).

Conceptual understanding is an important goal in learning in general but is particularly relevant in science education because such understanding is required to make sense of scientific phenomena. To understand means being able to construct meaningful knowledge, interpret and explain (Anderson, Krathwohl, \& Bloom, 2001). Students taught to develop a conceptual understanding will be more proficient at problem-solving, abstract reasoning, applying their knowledge to new situations, and more likely to connect to related information (Ormrod, 1999).

Sadler, Sonnert, Coyle, Cook-Smith, and Miller (2013) found that teachers' conceptual understanding of science concepts, to extent, influences students' conceptual understanding of the concept taught. Hence, teachers' content knowledge greatly improves students' understanding of science concepts and reduces alternative conceptions among students. Studies that rigorously investigate the relationship between teachers' knowledge and their students' gains in understanding of science concepts are rare (Baumert et al., 2010). Teachers' content knowledge potentially affects their choice of instructional practice and their students' achievement gains (Hill, Rowan, \& Ball, 2005). It is found that science teachers with strong content knowledge can better communicate scientific concepts and ideas and are skillfully able to engage students in the content (Ball, Thames, \& Phelps, 2008). Teachers with inadequate content knowledge mostly misrepresent the content to their students, resulting in students developing alternative conceptions (Ball et al., 2008).

In Ghana, the WAEC Chemistry Chief Examiner's reports have repeatedly identified weakness of most students in functional group detection under organic chemistry both in practical or theory examination (WAEC, 2001; 2003; 2004; 2005; 2007; 2012; 2014; 2016; 2017; 2018). These reports suggest that SHS chemistry students have challenges with the conceptual understanding of functional group detection. However, the reports were not clear about the nature of the challenge and whether there was a problem with the teaching and learning. It was, therefore, necessary to investigate whether chemistry teachers teaching functional groups through qualitative analysis in Ghanaian senior high schools had conceptual difficulties on the concept and hence, their inability to 
help their students develop the scientific conception of functional groups.

Johnston (2005) opined that what is simple to the chemistry teacher may not be so for the learner. Teachers with a better understanding of their learners' cognition should be better able to adapt their lessons to facilitate a more holistic understanding of the content (Azuka, Durujaiye. Okwuoza, \& Jekayinka, 2013; Ogembol, Otunga, \& Yaki, 2015; Unanma, Abugu, Dike, \& Umeobika, 2013). The teaching and learning process of science depends on the nature and structure of the discipline. Ferguson \& Bodner (2008) asserted that teachers should understand the nature of their content and that teachers' understanding of that will influence the way they teach, and consequently the way their learners learn the content (Childs \& Sheehan, 2009; Simsek, 2009, Tatli \& Ayas, 2013). Hence, the nature of the content also influences the way the subject is taught and learned. Innovative learning strategies, therefore could be used by teachers at all levels of chemistry education to enhance students' learning of chemistry (Eybe \& Schmidt, 2004). Teachers' deep and strong content knowledge is a necessary tool in a constructivist classroom (Adu-Gyamfi, Ampiah \& Appiah, 2018; Aregawi \& Meressa, 2017; Grayson, Anderson, \& Crossley, 2001; Özkaya, Üce, Saricayir, \& Sahin, 2006). This is because those teachers could provide students with opportunities to develop a deep understanding of concepts, internalize the concepts, and develop complex cognitive structures for connections to other bodies of knowledge. Taber (2011) reiterated that a good number of students make meaning of concepts in more or less similar ways as they are taught by their teachers. Hence, to investigate what is being learned, it is equally important to know the teacher's knowledge of a specific content; and the need for this current research.

Juriševič, Glažar, Pučko, and Devetak (2008) found that teachers undergoing training in the colleges and universities have conceptual difficulties with regards to learning of chemistry, and this greatly influences their future teaching. Chemistry teachers' difficulties in chemistry concepts are potentially transferable to their students, which mostly results in learners' misconceptions about chemistry (Chavan, 2017). Therefore, chemistry teachers should be well equipped with the subject matter to help teach students true conception and avoid misconceptions (Arokoyo \& Amadi, 2018; Delmang \& Gongden, 2016) on functional groups.

\section{ReseArCh Design}

The convergent mixed methods design procedures (Creswell \& Plano Clark, 2018) were adopted to investigating whether teachers demonstrate conceptual difficulties in teaching organic functional group detection to their SHS students. A diagnostic test was used through a cross-sectional survey to collect both quantitative and qualitative data on teacher conceptual difficulties on functional group detection. From the diagnostic test, the performance of teachers was analyzed using means, standard deviations, and percentages. This helped to determine whether teachers demonstrated full scientific understanding, partial scientific understanding, or no scientific understanding. After that we thematically analyzed the qualitative data to investigate whether teachers had conceptual difficulties when they demonstrated any partial scientific understanding of functional group detection. The quantitative and qualitative aspects were merged through discussion to investigate whether chemistry teachers had conceptual difficulties on functional groups detection they teach students.

\section{Sampling Procedure}

The research was carried out in the Central Region of the Republic of Ghana. Central Region was selected by the researchers for the study due to the school types, proximity, and researchers' familiarity within the area. There were 68 senior high schools in this region during the 2019/2020 academic year when the research was carried out. The 68 schools were stratified into six Class A schools, 18 Class B schools, and 32 Class $\mathrm{C}$ schools. Of the 68 schools, 55 offered students chemistry as one of their elective subjects. From the 55 schools, 18 were selected through the simple random procedures for Classes $\mathrm{B}$ and $\mathrm{C}$ schools and the purposive procedures for the Class A schools. That is, six schools each from the three classes of the school. However, during the period of the data collection, only 12 schools were available due to COVID-19 related issues and protocols. It was estimated that there were nine teachers teaching chemistry in the 12 schools giving an accessible population of 108 teachers. All chemistry teachers who had once taught organic chemistry and were willing and ready to respond to the diagnostic test were purposively selected for the research. The purposive selection of the teachers was because their experiences immensely contributed to the research. In all, 47 teachers were involved from the 12 schools.

\section{Data Collection Instrument}

The diagnostic test, Organic Qualitative Analysis Diagnostic Test for Teachers (OQADTT), was in two sections. Section A sought for biodata of teachers: age, sex, class of the school, and teaching experience. Section B was made of nine two-tier four-option multiple-choice test items. Teachers were required to correctly respond to each item by selecting one of the four options with a reason. The reason provided for selecting a particular option helped to explore the 
conceptual understanding of teachers. The other two tests items were not multiple-choice but essay-type. The essay-type items involved the detection and analysis of functional groups with organic reagents. Here, teachers' conceptual understanding and difficulty in conceptualizing functional groups were explored. That is, their ability to:

1. Identify some functional groups like alkenes, alkynes, alkanols, benzene, alkanoic acids, and alkyl alkanoates.

2. Write observation that will be envisaged when known oxidizing and reducing agents reacts with certain organic compounds.

Test items on OQADTT were constructed by the researchers. In designing the test, the researchers compared the items to standardized questions on functional group detections and organic reactions in chemistry textbooks and questions set by the WAEC for the West African Secondary School Certificate Examinations. The purpose of the comparison was to ensure the content validity of OQADTT. To also ensure face validity of the instrument, OQADTT was shown to two colleague chemistry teachers of author 1 and a colleague science educator of author2 for expert advice and critique on the content. The face validity helped improve the quality of OQADTT items before they were pilot-tested with ten teachers from senior high schools in the Sekondi-Takoradi Metropolis of the Western Region. The pilot-testing of OQADTT helped determine the difficulty and discrimination indices of the test items, which in turn helped improve the internal consistency of the instrument. Item 20 was modified into an alkanol undergoing a complete oxidation reaction to form alkenone. Items 5,7, 8, 9, 13, 17, and 18 were deleted as they had similarities with the measurement of benzene, alkanols, amides, alkanoic acids, combustion reactions of hydrocarbons, alkenes, and aldehydes, respectively on the essay-type items. The calculated KuderRichardson (KR) 21 coefficient of reliability was 0.74 after we deleted the seven items.

\section{Data Collection Procedure}

The research instrument (OQADTT) was administered by the researchers. During the administration of OQADTT, a brief discussion on the purpose of the research was held between the researchers and teachers. The briefing helped the research a lot as teachers appreciated the need to participate. After the briefing sessions, researchers found out if chemistry teachers have covered enough on organic chemistry in each school and that if they have been teaching organic chemistry in the last five years. The selected schools and teachers who had not covered enough were exempted from the research. Other schools were made to replace those selected but exempted schools. In all, it took four weeks to administer OQADTT.

\section{Vi. Data Processing and Analysis}

Each specific concept on OQADTT scores two marks, and this gave a total of 18 scores for the nine items. The two essay-type items had 13 specific concepts that gave a total of 26 scores. The total score from OQADTT was expected to be 44 . The structure of the level of understanding informing the scores was adapted from previous research in the area of conceptual understanding (Ültay \& Çalik, 2016) and modified to suit this research. The three levels of conceptual understanding were;

1. A full scientific understanding was the first level that went with correct content and reason responses; being two scores,

2. A partial scientific understanding was the second level that went with correct responses for either content or reason but not both; being one score, and

3. A no scientific understanding was the third level with incorrect responses for both content and reason; being zero score.

We used means, standard deviations, and percentages to analyze the data. A mean between 0.0 to 0.49 was considered a no scientific understanding, between 0.50 and 1.49 as a partial scientific understanding, and between 1.50 and 2.0 as a full scientific understanding. For the qualitative aspect, the explanations given by the selected teachers for any content response were open-coded and constantly compared. We then made meanings of them to develop themes to present any conceptual difficulties teachers had on organic functional group detection.

\section{Results}

To provide the answers on whether chemistry teachers teaching functional groups through qualitative analysis do demonstrate conceptual difficulties, we first investigated their levels of conceptual understanding. This was important as we needed to appreciate whether teachers demonstrated partial scientific understanding of functional group detection and to be able to investigate their conceptual difficulties. The results are presented in Table 1. In general, teachers demonstrated partial scientific understanding on functional group detection. This is because the mean scientific understanding of teachers on all items was 1.00 (SD = 0.894). 
Table 1: Levels of Teachers' Conceptual Understanding on Functional Groups Detection $(\mathrm{N}=47)$

\begin{tabular}{|c|c|c|c|c|c|c|c|c|}
\hline \multirow{3}{*}{ Item } & \multicolumn{6}{|c|}{ Understanding level } & \multirow{3}{*}{$M$} & \multirow{3}{*}{ SD } \\
\hline & \multicolumn{6}{|c|}{$\begin{array}{l}\text { No Scientific Partial Scientific Full Scientific } \\
\text { Understanding Understanding Understanding }\end{array}$} & & \\
\hline & $\mathrm{n}$ & $\%$ & $\mathrm{n}$ & $\%$ & $\mathrm{n}$ & $\%$ & & \\
\hline \multicolumn{9}{|l|}{ hydrocarbons } \\
\hline 6 & 12 & 25.5 & 10 & 21.3 & 25 & 53.2 & 1.28 & 0.852 \\
\hline 5 & 6 & 12.8 & 13 & 27.7 & 28 & 59.6 & 1.47 & 0.718 \\
\hline 10 & 5 & 10.6 & 17 & 36.2 & 25 & 53.2 & 1.43 & 0.683 \\
\hline 12 & 23 & 48.9 & 15 & 31.9 & 9 & 19.1 & 0.70 & 0.778 \\
\hline$\alpha 14 \mathrm{~B}$ & 22 & 46.8 & 0 & 0 & 25 & 53.2 & 0.89 & 1.005 \\
\hline$\beta 14 \mathrm{~B}$ & 25 & 53.2 & 0 & 0 & 22 & 46.8 & 0.94 & 1.009 \\
\hline $15 \beta$ & 23 & 48.9 & 0 & 0 & 24 & 51.1 & 1.02 & 1.011 \\
\hline 18 & 22 & 44.7 & 19 & 40.4 & 6 & 12.8 & 0.66 & 0.700 \\
\hline 8 & 5 & 10.6 & 17 & 36.2 & 25 & 53.2 & 1.43 & 0.683 \\
\hline 21 & 21 & 44.7 & 7 & 14.9 & 19 & 40.4 & 0.96 & 0.932 \\
\hline \multicolumn{9}{|l|}{ alkanols } \\
\hline 9 & 15 & 31.9 & 18 & 38.3 & 14 & 29.8 & 0.98 & 0.794 \\
\hline$\alpha 14 D$ & 23 & 48.9 & 0 & 0 & 24 & 51.1 & 1.02 & 1.011 \\
\hline$\beta 14 \mathrm{D}$ & 26 & 55.3 & 0 & 0 & 21 & 44.7 & 0.89 & 1.005 \\
\hline $15 \alpha$ & 18 & 38.3 & 0 & 0 & 29 & 61.7 & 1.23 & 0.983 \\
\hline 16 & 24 & 51.1 & 17 & 36.2 & 6 & 12.8 & 0.62 & 0.709 \\
\hline 20 & 27 & 57.4 & 0 & 0 & 20 & 42.6 & 0.85 & 1.000 \\
\hline \multicolumn{9}{|l|}{ alkanoic acid } \\
\hline 11 & 7 & 14.9 & 19 & 40.4 & 21 & 44.7 & 1.30 & 0.720 \\
\hline 13 & 17 & 36.2 & 13 & 27.7 & 17 & 36.2 & 1.00 & 0.860 \\
\hline$\alpha 14 \mathrm{~A}$ & 22 & 46.8 & 0 & 0 & 25 & 53.2 & 1.06 & 1.009 \\
\hline$\alpha 14 \mathrm{E}$ & 24 & 51.1 & 0 & 0 & 23 & 48.9 & 0.98 & 1.011 \\
\hline$\beta 14 \mathrm{~A}$ & 23 & 48.9 & 0 & 0 & 24 & 51.1 & 1.02 & 1.011 \\
\hline$\beta 14 \mathrm{E}$ & 27 & 57.4 & 0 & 0 & 20 & 42.6 & 0.85 & 1.011 \\
\hline 19 & 24 & 51.1 & 0 & 0 & 23 & 48.9 & 0.98 & 1.011 \\
\hline \multicolumn{9}{|l|}{ alkylalkanoates } \\
\hline 7 & 6 & 12.8 & 13 & 27.7 & 28 & 59.6 & 1.47 & 0.718 \\
\hline$\alpha 14 \mathrm{C}$ & 26 & 55.3 & 0 & 0 & 21 & 44.7 & 0.94 & 1.009 \\
\hline$\beta 14 C$ & 30 & 63.8 & 0 & 0 & 17 & 36.2 & 0.72 & 0.971 \\
\hline $15 \gamma$ & 23 & 48.9 & 0 & 0 & 24 & 51.1 & 1.02 & 1.011 \\
\hline \multicolumn{9}{|l|}{ amides } \\
\hline 17 & 22 & 46.8 & 11 & 23.4 & 14 & 29.8 & 0.83 & 0.868 \\
\hline \multicolumn{9}{|l|}{ alkanals and } \\
\hline alkanones & 34 & 72.3 & 2 & 4.3 & & 23.4 & & \\
\hline 22 & & & & & 11 & & 0.51 & 0.856 \\
\hline
\end{tabular}

For instance, to ascertain that propane readily dissolves in tetrachloromethane, Item 6 was used. The results from Table 1 show that $21.3 \%$ of the teachers at a mean of $1.28(\mathrm{SD}=0.852)$ demonstrated a partial scientific understanding of the concept. This indicates that $25.5 \%$ teachers had no scientific understanding, and $53.2 \%$ had a full understanding of the concept. Hence, teachers have a partial scientific understanding that propane readily dissolves in tetrachloromethane. To ascertain that alkenes and alkynes are organic compounds that usually undergo addition reactions, Item 5 was used. The results show that $27.7 \%$ of the teachers at a mean of $1.47(S D=0.718)$ demonstrated a partial scientific understanding of the concept. This indicates that $12.8 \%$ teachers had no understanding and $59.6 \%$ had a full scientific understanding of the 
concept. Hence, teachers have a partial scientific understanding that alkenes and alkynes are organic compounds that usually undergo addition reactions. On Item 10 , the results show that $36.2 \%$ of the teachers at a mean of $1.43(S D=0.683)$ demonstrated a partial scientific understanding on the fact that ethene decolorizes both $\mathrm{Br}_{2} / \mathrm{CCl}_{4}$ and acidified $\mathrm{KMnO}_{4}$. This indicate that $53.2 \%$ of the teachers fully understood and $10.6 \%$ had no understanding on the concept. Hence, teachers have a partial scientific understanding that ethene is an organic compound that decolorizes both $\mathrm{Br}_{2} / \mathrm{CCl}_{4}$ and acidified $\mathrm{KMnO}_{4}$. On Item 12, the results show that $31.9 \%$ of the teachers at a mean of 0.70 $(\mathrm{SD}=0.778)$ demonstrated a partial scientific understanding that propene gives a brown color solution with alkaline potassium tetraoxomanganate(VII). This indicates that $48.9 \%$ teachers had no understanding and $19.1 \%$ had a full scientific understanding of the concept. Hence, teachers have a partial scientific understanding that propene gives brown colour solution with alkaline potassium tetraoxomanganate (VII).

On Item $\alpha 14 \mathrm{~B}$ that investigated conceptual understanding of the formation of propene from the dehydration of propanol using concentrated tetraoxosulphate $(\mathrm{VI})$ acid, none of the teachers at a mean of $0.89(S D=1.005)$ demonstrated a partial scientific understanding, and $46.8 \%$ had no scientific understanding, and $53.2 \%$ demonstrated a full scientific understanding. Hence, teachers have no partial scientific understanding but a full understanding that propene is formed when propanol is dehydrated in the presence of concentrated tetraoxosulphate $(\mathrm{VI})$ acid and heat. To ascertain that an alkene functional group is present in propene, Item $\beta 14 \mathrm{~B}$ was used. The results show that none of the teachers at a mean of 0.94 $(S D=1.009)$ demonstrated a partial scientific understanding. This indicates that $46.8 \%$ teachers fully understood and $53.2 \%$ teachers did not understand the concept. Hence, teachers have no partial scientific understanding but a full scientific understanding that an alkene functional group is present in propene. On Item $15 \beta$ that investigated dehydration as a type of chemical reaction involved in the conversion of propanol to propene, the results show none of the teachers at a mean of $1.02(S D=1.011)$ demonstrated a partial scientific understanding, but $51.1 \%$ fully understood. and $48.9 \%$ demonstrated no scientific understanding of the concept. Hence, teachers demonstrate no partial understanding but a full understanding that dehydration is the type of chemical reaction involved in the conversion of propanol to propene.

To ascertain that 2-butyne is unsaturated and will decolorizes bromine solution, Item 18 was used. The results show that $40.4 \%$ of the teachers at a mean of $0.66(\mathrm{SD}=0.700)$ demonstrated a partial scientific understanding of the concept. This indicates that $46.7 \%$ of teachers had no scientific understanding and $12.8 \%$ of teachers had full scientific understanding of the concept. Hence, teachers have a partial scientific understanding that 2-butyne is unsaturated and can decolorize bromine solution. On Item 8, the results show that $36.2 \%$ of the teachers at a mean of $1.43(\mathrm{SD}=0.683)$ demonstrated a partial scientific understanding that complete hydrogenation of benzene gives cyclohexane. This indicates that $10.6 \%$ of teachers had no scientific understanding and $53.2 \%$ of teachers had full scientific understanding of the concept. Hence, teachers have a partial scientific understanding that complete hydrogenation of benzene gives cyclohexane. On Item 21, the results show that $14.9 \%$ of the teachers at a mean of $0.96(S D=0.932)$ demonstrated a partial scientific understanding that either bromine solution or acidified $\mathrm{KMnO}_{4}$ is used to distinguish between benzene and ethene. This indicates that $44.7 \%$ of teachers had no scientific understanding and $40.4 \%$ of teachers fully understood the concept. Hence, teachers have a partial scientific understanding that either bromine solution or acidified $\mathrm{KMnO}_{4}$ is used to distinguish between benzene and ethane.

In the area of detection of a functional group of alkanols, the results on Item 9 show that $38.3 \%$ of the teachers at a mean of $0.98(S D=0.794)$ demonstrated a partial scientific understanding that secondary alkanol undergoes a complete oxidation reaction to produce an alkenone. This indicate that $29.8 \%$ of teachers fully understood and $31.9 \%$ of teachers had no scientific understanding of the concept. Hence, teachers have a partial scientific understanding that secondary alkanol undergoes a complete oxidation reaction to produce an alkenone. To ascertain that ethanol and propanoic acid are produced when ethyl propanoate undergoes acid hydrolysis, Item $\alpha 14 \mathrm{D}$ was used. The results show that none of the teachers at a mean of $1.02(S D=1.011)$ demonstrated a partial scientific understanding. This indicates that $48.9 \%$ teachers had no scientific understanding and $51.1 \%$ of teachers had full understanding of the concept. Hence, teachers have no partial scientific understanding, but a full scientific understanding that ethanol and propanoic acid are produced when ethyl propanoate undergoes acid hydrolysis. On Item $\beta 14 \mathrm{D}$, the results show that none of the teachers at a mean of $0.89 \quad(S D=1.005)$ demonstrated a partial scientific understanding of the fact that alkanol and alkanoic acid functional groups are present when ethyl propanoate undergoes acid hydrolysis. This indicates that $44.7 \%$ of teachers fully understood, and $55.3 \%$ of teachers had no scientific understanding of the concept. Hence, teachers have no partial scientific understanding, but a full scientific understanding that alkanol and alkanoic acid functional groups are present when ethyl propanoate undergoes acid hydrolysis. To ascertain that that oxidation is the type of chemical reaction involved in the conversion of propanol to propanoic acid, Item $15 \alpha$ was used. The 
results show that none of the teachers at a mean of $1.23(\mathrm{~S} D=0.983)$ demonstrated partial scientific understanding of the concept. This indicates that most $(61.7 \%)$ teachers had full scientific understanding, and $38.3 \%$ of teachers had no understanding of the concept. Hence, teachers demonstrate no partial scientific understanding but a full scientific understanding that oxidation reaction occurs in the conversion of propanol to propanoic acid. On Item 16, the results show that $36.2 \%$ of the teachers at a mean of $0.62(S D=0.709)$ demonstrated partial scientific understanding of the fact that an alkanol reacts with yellow-colored potassium heptaoxodichromate (VI) solution and changes it to green. This indicates that $12.8 \%$ of teachers fully understood, and $51.1 \%$ of teachers demonstrated no understanding of the concept. Hence, teachers have a partial scientific understanding that an alkanol reacts with yellow-colored potassium heptaoxodichromate (VI) solution and changes it to green. On Item 20, the results show that none of the teachers at a mean of 0.85 $(S D=1.000)$ demonstrated a partial scientific understanding of the concept. This indicates that $57.4 \%$ of teachers demonstrated no scientific understanding, and $42.6 \%$ of teachers had full understanding on the concept. Hence, teachers demonstrate no partial scientific understanding but a full scientific understanding that yellow precipitate is formed when an alkanol is treated with a hot solution of iodine in sodium hydroxide.

In the area of detection of a functional group of alkanoic acids, Item 11 was used to investigate whether hydrogen gas is liberated when alkanoic acid reacts with sodium metal. The results from Table 1 show that $40.4 \%$ of the teachers at a mean of $1.30 \quad(S D=0.720)$ demonstrated a partial scientific understanding on the concept. This indicates that $14.9 \%$ of teachers demonstrated no scientific understanding, and $44.7 \%$ of teachers demonstrated a full scientific understanding of the concept. Hence, teachers demonstrate a partial scientific understanding that hydrogen gas is liberated when alkanoic acid reacts with sodium metal. On Item 13 , the results show that $27.7 \%$ of the teachers at a mean of $1.00 \quad(S D=0.860)$ demonstrated a partial scientific understanding of a complete oxidation of propanol to propanoic acid. This indicates that $36.2 \%$ of teachers demonstrated no scientific understanding, and $36.2 \%$ of teachers fully understood the concept. Hence, teachers have a partial scientific understanding that a complete oxidation of propanol in the presence of oxidizing agents such as potassium heptaoxodichromate (IV) and heat produces propanoic acid. To ascertain whether teachers understand that propanoic acid is produced when propanol undergoes oxidation reaction in the presence of acidified potassium dichromate $(\mathrm{VI})$, Item $\alpha 14 \mathrm{~A}$ was used. The results show that none of the teachers at a mean of $1.06(S D=1.009)$ demonstrated a partial scientific understanding of the concept, $46.8 \%$ of teachers demonstrated no scientific understanding, and 53.2\% of teachers had a full scientific understanding of the concept. Hence, teachers have no partial scientific understanding, but a full understanding that propanoic acid is produced when propanol undergoes oxidation reaction in the presence of acidified potassium dichromate(VI). On Item $\alpha 14 \mathrm{E}$, the results show that none of the teachers at a mean of 0.98 (SD =1.011) demonstrated a partial scientific understanding, $51.1 \%$ of teachers, no scientific understanding, and $48.9 \%$ of teachers fully understood the concept. Hence, teachers have no partial scientific understanding, but a full scientific understanding that both ethanol and propanoic acid are produced when ethyl propanoate undergoes acid hydrolysis. On Item $\beta 14 \mathrm{~A}$, the results show that none of the teachers at a mean of $1.02(S D=1.011)$ demonstrated a partial scientific understanding on the fact that an alkanoic acid functional group is present when propanol undergoes oxidation reaction in the presence of acidified potassium dichromate $(\mathrm{VI}), \quad 48.9 \%$ of teachers demonstrate no scientific understanding, and $51.1 \%$ of teachers had a full understanding of the concept. Hence, teachers have no partial scientific understanding, but a full scientific understanding that an alkanoic acid functional group is present when propanol undergoes oxidation reaction in the presence of acidified potassium dichromate(VI). On Item $\beta 14 \mathrm{E}$, the results show that none of the teachers at a mean of $0.85(S D=1.011)$ demonstrated a partial scientific understanding of the fact that both alkanol and alkanoic acid functional groups are present when ethyl propanoate undergoes acid hydrolysis. This indicates that $57.4 \%$ of teachers demonstrated no scientific understanding, and $42.6 \%$ of teachers fully understood the concept. Hence, teachers have no partial scientific understanding, but a full understanding that both alkanol and alkanoic acid functional groups are present when ethyl propanoate undergoes acid hydrolysis. On Item 19, the results show that none of the teachers at a mean of $0.98 \quad(S D=1.011)$ demonstrated a partial scientific understanding of the fact that carbon(IV) dioxide is evolved when propanoic acid reacts with sodium hydrogentrioxocarbonate(IV), $51.1 \%$ of teachers demonstrated no scientific understanding, and $48.9 \%$ of teachers fully understood the concept. Hence, teachers have no partial scientific understanding, but a full understanding that carbon (IV) dioxide is evolved when propanoic acid reacts with sodium hydrogentrioxocarbonate(IV).

In the area of detection of a functional group of alkyl alkanoates, Item 7 investigated whether teachers scientifically understand that ethyl methanoate is an ester and sweet-scented. The results show that $27.7 \%$ of the teachers at a mean of $1.47 \quad(S D=0.718)$ demonstrated a partial understanding of the concept, $12.8 \%$ of teachers have no scientific understanding, and $59.6 \%$ of teacher fully understood the concept. Hence, 
teachers demonstrate partial scientific understanding that ethyl methanoate is an ester, and hence, is sweetscented. On Item $\alpha 14 \mathrm{C}$, the results from Table 1 show that none of the teachers at a mean of $0.94(S D=1.009)$ demonstrated a partial scientific understanding, 55.3\% of teachers demonstrated no understanding, and $44.7 \%$ of teachers fully understood that ethyl propanoate is produced when propanoic acid reacts with ethanol. Hence, teachers have no partial understanding, but a full scientific understanding that ethyl propanoate is produced when propanoic acid reacts with ethanol. On Item $\beta 14 \mathrm{C}$, the results show that none of the teachers at a mean of $0.72(S D=0.971)$ demonstrated a partial scientific understanding of the fact that an alkyl alkanoate functional group is present in a product formed from chemical reaction between propanoic acid and ethanol. This indicates that $63.8 \%$ of teachers demonstrated no scientific understanding, and $36.2 \%$ of teachers fully understood the concept. Hence, teachers have no a partial understanding, but a full understanding that an alkyl alkanoate functional group is present in a product formed from chemical reaction between propanoic acid and ethanol. On Item $15 \gamma$, the results show that none of the teachers at a mean of 1.02 $(S D=1.011)$ demonstrated a partial scientific understanding of the fact that the conversion of propanol to ethyl propanoate is an esterification. This indicates that $48.9 \%$ of teacher demonstrated no scientific understanding, and $51.1 \%$ of teachers fully understood the concept. Hence, teachers have no partial understanding, but a full scientific understanding that the type of chemical reaction involved in converting propanol to ethyl propanoate is an esterification.

In the area of an amide functional group detection, Item 17 was used. The results show that $23.4 \%$ of the teachers at a mean of $0.83(S D=0.868)$ demonstrated a partial scientific understanding of the concept. This indicates that $46.8 \%$ of teachers demonstrated no scientific understanding, and $29.8 \%$ of teachers had a full understanding of the concept. Hence, teachers have a partial scientific understanding that ammonia gas is evolved when an amide is warmed with dilute sodium hydroxide solution.

In the area of the carbonyl groups, Item 22 was used to investigate whether teachers have an understanding that the ammoniacal silver nitrate or Fehling's solution is used to distinguish between alkanals and alkenones. The results from Table 1 show that only $4.3 \%$ of the teachers at a mean of 0.51 $(S D=0.856)$ demonstrated partial understanding of the concept. This indicates that $72.3 \%$ of teachers demonstrated no scientific understanding, and $23.4 \%$ of teachers had fully understood the concept. Hence, teachers have a partial understanding that either the ammoniacal silver nitrate or Fehlings solutions can be used to distinguish between alkanals and alkenones.
To further investigate the conceptual difficulties teachers may have on teaching organic functional group detection to students, the explanation aspects of the teachers who demonstrated partial scientific understanding were examined. This was important as it helps identify any alternative conceptions and other factual difficulties teachers had on functional group detection. For instance, Item 5 was less difficult for teachers with an index of 0.87 . Of the 47 teachers, none of them demonstrated any alternative conceptions, but $27.66 \%$ of teachers' explanations were in the category of factual difficulties relating to alkenes and alkynes undergoing an addition reaction. The evidence of factual difficulties in a teacher's explanations is:

Factual difficulties: teachers explained that hydrocarbons undergo an addition reaction. An excerpt is:

alkenes and alkynes are hydrocarbons hence undergo addition reactions (Teacher, 23).

Also, Item 6 was less difficult for teachers with an index of 0.74 . Of the 47 teachers, an equal proportion (14.93\%) of teachers' explanations were alternative conceptions and factual difficulties relating to propane readily dissolves in tetrachloromethane, but not alkene and alkyne molecules. The evidence of alternative conceptions and factual difficulties is:

Alternative conceptions: alkenes and alkynes are polar compounds and thus, decolorize polar tetrachloromethane. An excerpt is:

alkenes and alkynes are polar compounds thus decolorize polar tetrachloromethane" (Teacher, 6).

Both alkenes and alkynes are polar ... the reason why they can decolorize tetrachloromethane (Teacher, 17).

Factual difficulties: alkenes and alkynes usually undergo an addition reaction because the pi bonds in the carbon-carbon multiple bonds are very strong to break by tetrachloromethane solution. An excerpt is:

alkenes and alkynes undergo an addition reaction because pi bonds in the carbon-carbon double and triple bonds are strong hence unreactive to polar tetrachloromethane (Teacher, 42).

Item 8 was less difficult for teachers with an index of 0.87 . Of the 47 teachers, an equal proportion (25.37\%) of teachers' explanations were categorized into alternative conceptions and conceptual difficulties. The evidence of alternative conceptions and factual difficulties is:

Alternative conceptions: hydrogenation of benzene produces cycloalkane compounds. An excerpt is:

benzene hydrogenate to produce cyclohexane because benzene is a cyclic compound with double bonds between each other carbon atoms (Teacher, 31). 
... when hydrogen is added to benzene, the double bonds break and cyclohexane is formed (Teacher, 10).

Factual difficulties: Some teachers simply mentioned that benzene hydrogenates to form hexane with no scientific explanation. An excerpt is:

complete hydrogenation of benzene produces hexane (Teacher, 24).

Benzene is hydrogenated to form hexane (Teacher, 33).

Item 10 was less difficult for teachers with an index of 0.89 . Of the 47 teachers, an equal proportion (36.17\%) of teachers' explanations were alternative conceptions and factual difficulties, respectively, relating to ethene decolorizes both $\mathrm{Br}_{2} / \mathrm{CCl}_{4}$ and acidified $\mathrm{KMnO}_{4}$. The evidence of alternative conceptions and factual difficulties is:

Alternative conceptions: (i) ethane is saturated and hence, decolorizes $\mathrm{Br}_{2} / \mathrm{CCl}_{4}$ and acidified $\mathrm{KMnO}_{4}$. Excerpts are:

Ethane is an alkane, and being saturated molecule changes $\left(\mathrm{Br}_{2} / \mathrm{CCl}_{4}\right)$ and acidified $\left(\mathrm{KMnO}_{4}\right)$ solutions white ppt (Teacher, 25).

Ethane is saturated and all saturated organic compounds change the color of acidified $\mathrm{KMnO}_{4}$ (Teacher, 6).

(ii) propane to decolorize $\mathrm{Br}_{2} / \mathrm{CCl}_{4}$ and acidified $\mathrm{KMnO}_{4}$. An excerpt is:

propane changes $\mathrm{Br}_{2} / \mathrm{CCl}_{4}$ and acidified $\mathrm{KMnO}_{4}$ to colorless (Teacher, 12).

Factual difficulties: some of the teachers could only restate that ethene changed $\left(\mathrm{Br}_{2} / \mathrm{CCl}_{4}\right)$ and acidified $\left(\mathrm{KMnO}_{4}\right)$ solutions with no justification for the process. The excerpts are:

... ethene is the compound as it changes color of $\left(\mathrm{Br}_{2} / \mathrm{CCl}_{4}\right)$ and acidified $\left(\mathrm{KMnO}_{4}\right)$ solutions (Teacher, 39).

ethene changes color of $\left(\mathrm{Br}_{2} / \mathrm{CCl}_{4}\right)$ and acidified $\left(\mathrm{KMnO}_{4}\right)$ solutions (Teacher, 46).

Item 12 was difficult for teachers with an index of 0.51 . Of the 47 teachers, $31.91 \%$ of teachers' explanations were alternative conceptions with no factual difficulties relating to propene gives brown color solution with alkaline potassium tetraoxomanganate(VII). The evidence of alternative conceptions is:

Alternative conceptions: (i) propane reacts with alkaline potassium tetraoxomanganate(VII) to give a brown color. Excerpts are:

propane reacts with alkaline potassium tetraoxomanganate(VII) to give a brown color (Teacher, 27)

propane reacts with alkaline potassium tetraoxomanganate(VII) solution to give a brown color because oxidation states of Manganese reduces from
+7 which is purple color to +2 which is a brown color (Teacher, 19).

Item 18 was moderately difficult for teachers with an index of 0.53 . Of the 47 teachers, $19.15 \%$ of teachers' explanations were alternative conceptions and $21.28 \%$ were factual difficulties relating to 2-butyne is unsaturation and thus, decolorizes bromine solution. The evidence of alternative conceptions and factual difficulties is:

Alternative conceptions: (i) 2-butyne is an alkane and thus decolorizes bromine solution. An excerpt is:

alkane such as 2-butyne decolorizes bromine solution (Teacher, 19).

Factual difficulties: some teachers did not know that 2butyne is an unsaturated hydrocarbon. An excerpt is:

2-butyne contains alkanoic functional group acid; hence, changes color of bromine solution to colorless (Teacher, 35).

Also, Item 21 was moderately difficult for teachers with an index of 0.55 . Of the 47 teachers, $19.15 \%$ of teachers' explanations were alternative conceptions and $2.13 \%$ were factual difficulties relating to bromine solution or acidified $\mathrm{KMnO}_{4}$ used to distinguish between benzene and ethene. The evidence of alternative conceptions and factual difficulties is:

Alternative conceptions: (i) bromine atom is used to distinguish between benzene and ethene. An excerpt is:

benzene and ethene is differentiated using bromine atom (Teacher, 3).

the bromine atom in bromine solution can be used to differentiate ethene and benzene (Teacher, 17).

Factual difficulties: (i) some teachers did not know that indicators are not reagents for detection of functional groups, but that of titration. An excerpt is:

benzene changes phenolphthalein from colorless to pink but ethene is unreactive to phenolphthalein (Teacher, 8).

Item 9 was less difficult for teachers with an index of 0.68 . Of the 47 teachers, $38.30 \%$ of teachers' explanations were alternative conceptions with no factual difficulties relating to secondary alkanol undergoes a complete oxidation to produce an alkenone. The evidence of alternative conceptions is:

Alternative conceptions: (i) the presence of the two hydroxyl groups on secondary alkanols oxidize completely to produce ketones. An excerpt is:

secondary alkanols undergo complete oxidation to produce alkenone because in secondary alcohols there are two hydroxyl $(-\mathrm{OH})$ groups present hence forming an alkenone" (Teacher, 12).

usually for secondary alcohols the hydroxyl groups are two on the carbon giving alkenone on complete oxidation (Teacher, 5). 
Factual difficulties: (i) some teachers only stated that secondary alkanols can form alkenones with no further explanation. An excerpt is:

Secondary alkanols can form alkenones (Teacher, 28).

Item 16 was very difficult for teachers with an index of 0.43 . Of the 47 teachers, $21.28 \%$ of teachers' explanations were alternative conceptions and $14.89 \%$ were factual difficulties relating to alkanol reacts with a yellow color potassium heptaoxodichromate(VI) solution, and changes it to green. The evidence of alternative conceptions and factual difficulties is:

Alternative conceptions: (i) alkanols react with yellow potassium heptaoxodichromate $(\mathrm{VI})$ solution to form white precipitate. An excerpt is:

alkanol react with yellow color of potassium heptaoxodichromate(VI) solution to form a white precipitate (Teacher, 5).

Items 11 was less difficult for teachers with an index of 0.83 . Of the 47 teachers, $40.43 \%$ of teachers' explanations were alternative conceptions without any factual difficulties relating to hydrogen gas is liberated when alkanoic acid reacts with sodium metal. The evidence of alternative conceptions is:

Alternative conceptions: (i) a black precipitate is formed when alkanoic acid reacts with sodium metal. An excerpt is:

propanoic acid reacts with sodium metal to produce black precipitate (Teacher, 16).

(ii) carbonyl group reacts with sodium metal to liberate a hydrogen gas. An excerpt is:

a hydrogen gas is liberated when alkanals reacts with sodium metal (Teacher, 32).

Item 13 was moderately difficult for teachers with an index of 0.64 . Of the 47 teachers, $27.66 \%$ of teachers' explanations were alternative conceptions without any factual difficulties relating to a complete oxidation of propanol produces propanoic acid. The evidence of alternative conceptions is:

Alternative conceptions: complete oxidation of propanol produces propyl propanoate. An excerpt is:

Propyl propanoate is produced when propanol oxidizes completely (Teacher, 32).

Item 7 was less difficult for teachers with an index 0.85 . Of the 47 teachers, $27.66 \%$ of teachers' explanations were in the category of factual difficulties without any alternative conceptions relating to the sweet scent associated with alkyl alkanoate functional group detection. The evidence of factual difficulties is:

Factual difficulties: (i) some teachers did not know that methanamide is not an ester. An excerpt is:

methanamide is an ester so is sweet-scented (Teacher, 32). (ii) some teachers did not know that sodium ethanoate is a salt but an ester. An excerpt is:

sodium ethanoate is an ester so is sweet-scented (Teacher, 17).

If sodium ethanoate is sweet-centred, then is likely an ester (Teacher, 23)

Item 17 was moderately difficult for teachers with an index of 0.51 . Of the 47 teachers, $12.77 \%$ of teachers' explanations were alternative conceptions, and $10.64 \%$ were factual difficulties relating to ammonia gas is evolved when amide is warmed with dilute sodium hydroxide solution. The evidence of alternative conceptions and factual difficulties is:

Alternative conception: hydrogen gas is evolved when amide reacts with dilute sodium hydroxide solution. An excerpt is:

hydrogen gas is liberated when amide reacts with dilute sodium hydroxide solution (Teacher, 41).

Item 22 was very difficult for teachers with an index of 0.28 . Of the 47 teachers, an equal proportion $(4.26 \%)$ of teachers' explanations were alternative conceptions and factual difficulties relating to the Tollen's reagent or Fehling's solutions is used qualitatively to distinguish between carbonyl functional groups. Most of the teachers failed to provide reasons for the options they selected. Evidence of conceptual difficulties is:

Factual difficulties: aldehydes react with Tollen's reagent to form an acidic solution. An excerpt is:

aldehyde like propanal $\left(\mathrm{CH}_{3} \mathrm{CH}_{2} \mathrm{CHO}\right)$ reacts with Tollen's reagent to form acid solutions (Teacher, 16).

It reacts with Tollen's reagent to produce an acid (Teacher, 9).

\section{Vili. Discussion}

Teachers' demonstration of the low (partial) level of conceptual understanding of functional group detection is not only limited to hydrocarbons but nonhydrocarbons (such as alkanols, alkanoic acids, alkyl alkanoates, amides, alkanals, and alkenones) as well. This low level of conceptual understanding of detection of functional groups of saturation and unsaturation carbon compounds means that teachers are not rightly addressing the targeted specific objectives of the curriculum (MOE, 2010), where students are to test for saturation and unsaturation using acidified and alkaline purple $\mathrm{KMnO}_{4}, \mathrm{Br}_{2} / \mathrm{H}_{2} \mathrm{O}$. Teachers may not only have problems with enacting the curriculum (MOE, 2010) with appropriate pedagogical knowledge but may have problems of content knowledge of that they are supposed to teach to students. This is also evident as teachers demonstrate a low conceptual understanding of functional group detection of benzene using cold dilute $\mathrm{KMnO}_{4}, \mathrm{Br}_{2} / \mathrm{H}_{2} \mathrm{O}$ 
or $\mathrm{Br}_{2} / \mathrm{CHCl}_{3}$, and to test for alkanals and alkenones using 2, 4-dinitrophenylhydrazine, Fehling's or Benedict's solution, and Tollen's reagent (ammoniacal silver nitrate). Teachers could be just transferring information (Jonassen, Peck, \& Wilson, 1999) on organic chemistry from textbooks to their students with no meaningful learning from both sides. Teachers may have not sufficient mental models (Konicek-Moran \& Keeley, 2015) of functional groups of organic compounds. This is because teachers have a low conceptual understanding that alkanols change yellow heptaoxodichromate $(\mathrm{VI})$ solution green. These conceptual difficulties could account for teachers' inability to demonstrate a full scientific understanding of functional group detection but a partial scientific understanding, and even no scientific understanding in some instances. Not only is functional group detection under organic chemistry difficult for students (Goh et al., 1987), but also difficult for teachers who teach the students. Teachers' conceptual difficulties in detecting all functional groups either through the use of suitable organic reagents or the use of chemical reactions could be partly due to their insufficient knowledge of organic chemistry (Coll \& Treagust, 2001; Nicoll, 2001) when they were in high school or college students, their inability to identify chemical structures of organic compounds, and give correct names of these organic compounds (Adu-Gyamfi et al., 2017).

Also, the results showed that even though teachers are unable to identify most organic chemical reactions, the very few who are able fail to state and explain clearly the functional group present in those compounds. Hence, teachers are unable to give correct chemical structures of organic compounds undergoing chemical reactions. Teachers demonstrate factual difficulties, and alternative conceptions on functional group detection. Alternative conceptions seem to be a common phenomenon with students about chemical concepts globally, and the same can be said to teachers under organic qualitative analysis where functional groups are detected. Teachers in this study are demonstrating alternative conceptions, and other factual difficulties of functional group detection and that could be a contributing factor to students' alternative conceptions on chemical concepts. Teachers being a contributing factor to students' alternative conceptions is a confirmation of conceptual misunderstanding (a category of alternative conceptions) based on teacher's inability to use chemistry lessons to help students challenged their preconceived notions and nonscientific beliefs they bring to the classroom (Adu-Gyamfi \& Ampiah, 2019).

Teachers' demonstration of a wide range of factual difficulties and alternative conceptions of functional group detection could be partly due to the difficult nature of organic qualitative analysis (Stieff, 2007). Organic chemistry is known to be difficult for students. These teachers likely had difficulties learning the content at the high school and college levels and even at the university hence, their possible difficulties in teaching the concept. The nature of the content influences the way the subject is taught and learned (Tatli \& Ayas, 2013). This implies that teachers' difficulties in conceptualizing difficult content are potentially transferable to their students, resulting in learners' alternative conceptions about the concepts (Chavan, 2017).

Teachers' alternative conceptions and factual difficulties could be partly due to teachers' weak content knowledge. Teachers' deep and strong content knowledge is a necessary tool in students' learning (Adu-Gyamfi et al., 2018; Aregawi \& Meressa, 2017). A good number of students make meaning of concepts in similar ways as their teachers (Taber, 2011). Teachers' understanding of science content influences the way they teach, and consequently, the way their learners learn the content (Childs \& Sheehan, 2009; Greenbowe \& Schroeder, 2008; Simsek, 2009, Tatli \& Ayas, 2013). Teachers weak content knowledge could partly be due to teachers' demonstration of factual difficulties: which are teachers' conceptions developed from false ideas learned at the early ages and have remained unchallenged; lack of preparation before teaching the content; not specializing in chemistry at the university level; lack of frequent teaching of organic chemistry and functional groups content to students.

If WAEC Chief Examiner on chemistry complaints about students' poor show on organic chemistry, then the study shows that what students learn is equally dependent on the teacher's knowledge of that specific content. The results show that teachers, just as their students, also have little knowledge about organic reagents needed to test for the various functional groups, and give exact colour changes that occurs during these functional groups detection. Teachers also fail to provide names and explain reagents needed to detect for these functional groups. For instance, teachers have factual difficulties distinguishing reactions between saturation and unsaturation, primary and secondary alkanols, alkyl alkanoates, amides, and alkanals and alkenones. The results further show that teachers have factual difficulties and alternative conceptions in identifying the name of particular chemical reaction such as oxidation, dehydration and esterification. This implies that not only do teachers have conceptual difficulties in providing and predicting final product in organic reactions with reasons (Tang, Zain, \& Abdullah, 2010), but will find it difficult to teach them. This study also confirms an earlier work (Goh et al., 1987) that qualitative analysis (functional group detection) is difficult and that teachers who do not have adequate and sufficient understanding of the scientific concept can misrepresent the content to 
their students, causing them to have misunderstandings (Ball et al., 2008).

\section{iX. Conclusion}

The study has shown that functional group detection under organic qualitative analysis was difficult for teachers and they, therefore, demonstrate conceptual difficulties on the concept. The teachers' conceptual difficulties were qualitatively seen as alternative conceptions and factual difficulties. Those alternative conceptions and factual difficulties were seen under various functional groups as saturated and unsaturated hydrocarbons, alkanols, alkanoic acids, alkyl alkanoates, alkenones and aldehydes, and amides. The study has added to the literature that alternative conceptions exist in functional group detection as there are in other areas of chemistry. As teachers demonstrated a partial scientific conceptual understanding of functional group detection, the Ministry of Education through the Ghana Education Service should liaise with the teacher education universities to organise short courses for teachers to help upgrade their content knowledge in chemistry. And as teachers' factual difficulties and alternative conceptions existed on functional group detection, chemistry educators and researchers should design and develop instructional strategies that challenge alternative conceptions among teachers.

\section{References Références Referencias}

1. Adu-Gyamfi, K., \& Ampiah, J. G. (2019). Students' alternative conceptions associated with application of redox reactions in everyday life. Asian Education Studies, 4(1), 29-38. doi:10.20849/aes.v4i1.590

2. Adu-Gyamfi, K., Ampiah, J. G., \& Agyei, D. D. (2015). High school chemistry students' alternative conceptions of $\mathrm{H}_{2} \mathrm{O}, \mathrm{OH}^{-}$, and $\mathrm{H}^{+}$in balancing redox reactions. International Journal of Development and Sustainability, 4(6), 744-758.

3. Adu-Gyamfi, K., Ampiah, J. G., \& Agyei, D. D. (2018). Teachers' problems of teaching of oxidationreduction reactions in high schools. European Journal of Education Studies, 5(5), 53-71. Doi: 105281/zenodo.1471731

4. Adu-Gyamfi, K., Ampiah, J. G., \& Appiah, J. Y. (2017). Students' difficulties in IUPAC naming of organic compounds. Journal of Science and Mathematics Education, 6(2), 77-101.

5. Anderson, L. W., Krathwohl, D. R., \& Bloom, B. S. (2001). A taxonomy for learning, teaching, and assessing: A revision of Bloom's taxonomy of educational objectives. Boston: Allyn \& Bacon.

6. Aregawi, B. Z., \& Meressa, H. M. (2017). How to improve students' participation in chemistry class: The case of $2^{\text {nd }}$ Year chemistry students taking the course practical organic chemistry. International
Journal of Engineering Development and Research, 5(4), 1397-1401.

7. Arokoyo, A. A., \& Amadi, J. C. (2018). Analytical survey of students' attitudes towards teaching and learning of Mathematics and Chemistry in senior secondary schools. International Journal of Scientific Research and Innovative Technology, 5(9), 12-23.

8. Azuka, B. F., Durujaiye, D., Okwuoza, S. D., \& Jekayinka, O. (2013). Attitudes of primary mathematics teachers towards the use of activitybased learning methods in teaching mathematics in Nigeria schools. International Journal of Educational Learning, 1(1), 22-36.

9. Ball, D., Thames, M. H., \& Phelps, G. (2008). Content knowledge for teaching: What makes it special? Journal of Teacher Education, 59(5), 389-407.

10. Baumert, J., Kunter, M., Blum, W., Brunner, M., Voss, T., Jordan, A., Klusmann, U., \& Tsai, Y. M. (2010). Teachers' mathematical knowledge, cognitive activation in the classroom, and student progress. American Educational Research Journal, 47(1), 133-180.

11. Bodner, G. M. (1986). Constructivism: A theory of knowledge. Journal of Chemical Education, 63(10), 873-875.

12. Chavan, R. (2017). Difficulties encountered by science teachers during teaching concepts of science difficulties encountered by science teachers during teaching concepts of science. Physical Science Education Journal, 1, 1-9.

13. Childs, P. E., \& Sheehan, M. (2009). What's difficult about chemistry? An Irish perspective. Chemistry Education Research and Practice, 10, 204-218.

14. Coll, R. K., \& Treagust, D. F. (2001). Learners' mental models of chemical bonding. Research in Science Education, 3(1): 357-382.

15. Cooley, J. H., \& Williams, R. V. (1999). Qualitative analysis in the beginning organic laboratory. Journal of Chemical Education, 76, 1117-1120.

16. Creswell, J. W., \& Plano Clark, V. L. (2018). Designing and conducting mixed methods research ( $3^{\text {rd }}$ ed.). Thousand Oaks, California: SAGE Publications, Inc.

17. Darmofal, D. L., Soderholm, D. H., \& Brodeur, D. R. (2002). Using concept maps and concept questions to enhance conceptual understanding. Paper presented at the Frontiers in Education, 2002. FIE 2002. $32^{\text {nd }}$ Annual. http://dx.doi.org/10.1109/fie. 2002.1157954

18. Deci E. L., Vallerand R. J., Pelletier L. G., \& Ryan, R. M. (1991). Motivation and education: the selfdetermination perspective, Journal of Education and Psychology, 26(3), 325-346.

19. Delmang, T. K., \& Gongden, E. J. (2016). Ameliorating students' performance and attitude towards chemistry through chemistry problem- 
solving techniques. International Journal of Scientific Research in Education, 9(2), 41-47.

20. Domin, D. S., Al-Masum, M., \& Mensah, J. (2008). Students' categorizations of organic compounds. Chemistry Education Research and Practice, 9, 114-121.

21. Driver, R., Asoko, H., Leach, J., Scott, P., \& Mortimer, E. (1994). Constructing scientific knowledge in the classroom. Educational researcher. Journal of Science Education, 23(7), 5-12.

22. Eybe, H. \& Schmidt, H. J. (2004). Group discussions as a tool for investigating students' concepts. Chemistry Education Research and Practice, 5(3), 265-280.

23. Ferguson, R., \& Bodner, G. M. (2008). Making sense of the arrow-pushing formalism among chemistry majors enrolled in organic chemistry, Chemistry Education Research and Practice, 9, 102-113.

24. Goh, N. K., Toh, K. A., \& Chia, L. S. (1987). The effect of modified laboratory instruction on students' achievement in chemistry practical. Singapore: Institute of Education.

25. Grayson, D. J., Anderson, T. R., \& Crossley, L. G. (2001). A four level framework for identifying and classifying student conceptual and reasoning difficulties. International Journal of Science Education 23, 611-622.

26. Greenbowe, T. J., \& Schroeder, D. (2008). "Implementing POGIL in the lecture and the science writing Heuristic in the laboratory. Student perceptions and performance in undergraduate organic chemistry", Chemistry Education Research and Practice, 9, 149-156.

27. Hassan, A. K., Hill, R. A., \& Reid, N. (2004). Ideas underpinning success in an introductory course in organic chemistry. The Royal Society of Chemistry: University Chemistry Education, 8, 40-51.

28. Hill, H. C., Rowan, B., \& Ball, D. (2005). Effects of teachers 'mathematical knowledge for teaching on student achievement. American Educational Research Journal, 42, 371-406.

29. Johnston, J. (2005). Early explorations in Science. ( $2^{\text {nd }}$ ed.). Maidenhead: Open University Press.

30. Jonassen, D. H., Peck, K. L., \& Wilson, B. G. (1999). Learning with technology: A constructivist perspective. Upper Saddle River, NJ: Merrill Publishing.

31. Juriševič, M., Glažar, S. A., Pučko, C. R., \& Devetak, I. (2008). Intrinsic motivation of pre-service primary school teachers for learning chemistry in relation to their academic achievement. International Journal of Science Education, 30(1), 87-107.

32. Konicek-Moran, R., \& Keeley, P. (2015). Teaching for conceptual understanding in science. National Science Teachers Association: NSTA Press.
33. Matthews, P. (2011). Advanced chemistry. New York: Cambridge University Press.

34. Ministry of Education. (2010). Teaching syllabus for chemistry: Senior high school 1- 3. Accra: Author.

35. Nakhleh, M. B. (1992). Why some students don't learn chemistry, Journal of Chemical Education, 69(3). 191-196.

36. O'Dwyer, A., \& Childs, P. E. (2017). Who says organic chemistry is difficult? Exploring perspectives and perceptions. Journal of Mathematics, Science and Technology Education, 13(7), 3599-3620.

37. Ogembol, J. O., Otunga, H., \& Yaki, R. N. (2015). Students' and Teachers' Attitude and Performance in Chemistry in Secondary Schools. Global Journal of Interdisciplinary Social Science, 4(3), 39-43.

38. Ormrod, J. E. (1999). Human learning. New Jersey: Merrill-Prentice Hall.

39. Özkaya, A. R., Üce, M., Saricayir, H., \& Sahin, M. (2006). Effectiveness of conceptual change-oriented teaching strategy to improve students' understanding of galvanic cells. Journal of Chemical Education, 83(11), 17-19.

40. Pınarbaşı, T., \& Canpolat, N. (2003). Students' understanding of solution chemistry concepts. Journal of Chemical Education, 80(11), 1328-1332.

41. Petrucci, R. H., Herring, F. G., Madura, J. D., \& Bissonnette, C. (2017). General chemistry: Principle $\&$ modern applications $\left(11^{\text {th }}\right.$ ed.). Ontario: Person Canada Inc.

42. Rice, L. (2016). Organic chemistry through visualization. Dublin: Dublin City University.

43. Sadler, P. M., Sonnert, G., Coyle, H. P., Cook-Smith, N., \& Miller, J. L. (2013). The influence of teachers' knowledge on student learning in middle school physical science classrooms. American Educational Research Journal, 50(5), 1020-1049.

44. Schwartz, L. D. (1993). The construction and analogical transfer of symbolic visualizations, Journal of Research in Science Teaching, 30(10), $1309-1325$.

45. Simsek, U. (2009). The effect of animation and cooperative learning on chemistry students academic achievement and conceptual understanding about aqueous solution, World Applied Science Journal. 7(1), 23-33.

46. Smith, P. L., \& Ragan, T. J. (1999). Instructional design. New York, NY: Wiley.

47. Stieff, S. (2007). Mental rotation and diagrammatic reasoning in science curriculum and instruction. Learning and Instruction, 17, 1-16.

48. Strickland, A. M., Kraft, A., \& Bhattacharyya, G. (2010). What happens when representations fail to represent? Graduate students' mental models of organic chemistry diagrams. Chemistry Education Research and Practice, 11(4), 293-301. 
49. Taber, K. S. (2002). Alternative conceptions in chemistry: Prevention, diagnosis and cure? London: The Royal Society of Chemistry.

50. Taber, K. S. (2011). Constructivism as educational theory: Contingency in learning, and optimally guided instruction. In J. Hassaskhah (Ed.), Educational theory (pp. 39-61), Hauppauge, NY: Nova Science Publishers, Inc.

51. Tang, A. Y. C., Zain, M, S., \& Abdullah, R. (2010). Development and evaluation of a chemistry educational software for learning organic reactions using qualitative reasoning. International Journal of Education and Information Technologies, 3(4), 129-138.

52. Tatli, Z., \& Ayas, A. (2013). Effect of a virtual chemistry laboratory on students' achievement. Educational Technology \& Society, 16(1), 159-170.

53. Ültay, N., \& Çalik, M. (2016). A Comparison of Different Teaching Designs of 'Acids and Bases' Subject. Eurasia Journal of Mathematics, Science \& Technology Education, 12(1), 57-86.

54. Unanma, A. O., Abugu, H. O., Dike, R. C., \& Umeobika U. C. (2013). Relationship between teachers' educational qualifications and student's achievement in chemistry: A Case Study of Owerri West LGA. Journal of Research \& Method in Education, 1(1), 5-10.

55. West African Examinations Council. [WAEC]. (2001). Chief examiner's report on West African senior school certificate examination. May/June chemistry practical. Accra: Wisdom Press.

56. West African Examinations Council. [WAEC]. (2003). Chief examiner's report on West African senior school certificate examination. May/June chemistry practical. Accra: Wisdom Press.

57. West African Examinations Council. [WAEC]. (2004). Chief examiner's report on West African senior school certificate examination. May/June chemistry practical. Accra: Wisdom Press.

58. West African Examinations Council. [WAEC]. (2005). Chief examiner's report on West African senior school certificate examination. May/June chemistry practical. Accra: Wisdom Press.

59. West African Examinations Council. [WAEC]. (2006). Chief examiner's report on West African senior school certificate examination. May/June chemistry practical. Accra: Wisdom Press.

60. West African Examinations Council. [WAEC]. (2007). Chief examiner's report on West African senior school certificate examination. May/June chemistry practical. Accra: Wisdom Press.

61. West African Examinations Council. [WAEC]. (2012). Chief examiner's report on West African senior school certificate examination. May/June chemistry practical. Accra: Wisdom Press.

62. West African Examinations Council. [WAEC]. (2014). Chief examiner's report on West African senior school certificate examination. May/June chemistry practical. Accra: Wisdom Press.

63. West African Examinations Council. [WAEC]. (2015). Chief examiner's report on West African senior school certificate examination. May/June chemistry practical. Accra: Wisdom Press.

64. West African Examinations Council. [WAEC]. (2016). Chief examiner's report on West African senior school certificate examination. May/June chemistry practical. Accra: Wisdom Press.

65. West African Examinations Council. [WAEC]. (2017). Chief examiner's report on West African senior school certificate examination. May/June chemistry practical. Accra: Wisdom Press.

66. West African Examinations Council. [WAEC]. (2018). Chief examiner's report on West African senior school certificate examination. May/June chemistry practical. Accra: Wisdom Press.

67. Yong, W. (1994). Developments in chemical education in China-STS education and social organic chemistry. Journal of chemical education, $71(6), 509$. 